\title{
Raising guardrails: The role of the political commentator in a post-expert age
}

\author{
Paul D. Williams \\ paul.williams@griffith.edu.au
}

\begin{abstract}
Political commentary is a key component of news coverage in any liberal democracy. Yet theorising the role played by political commentators in a rapidly transforming media sphere - further destabilised by voters' increasing mistrust of expertise and of political and media institutions - is rare in the social science literature. This article adopts a mixed methodological approach to argue that political commentators today perform one or more of three functions - 'public educator', 'value educator' and 'polemicist' - with commentators now falling into one of seven types. Given the broadening and flattening of news media dissemination and consumption - and arguably the 'dumbing down' and 'shallowing out' of news media coverage in a postmodern social media age where truth and facts are too often subordinated by rhetoric and opinion - this article argues that the role of the academic political commentator is now more critical than ever. It also argues that academic commentators must offer not only objective descriptive analysis of political events but also potentially subjective normative analysis - in effect, narrative 'guardrails' - to remind voters of what is and is not acceptable political behaviour in a 'post-truth' anti-expert age.
\end{abstract}

\section{Introduction}

The role of the political commentator was relatively easy to define in a pre-digital era. Years before the World Wide Web, Australian voters evaluated political events on information gleaned only from printed newspapers, radio and television news bulletins. The expert commentator then was almost exclusively a university-based academic who, with postgraduate qualifications and a record of research in political science, would regularly be called upon - as a neutral 'voice of reason' - to describe political institutions and their role in the day's events (Shuman and Greenberg, 2003: 220).

Identifying the political commentator and their role today is far more challenging. Where traditional media erected barriers between expert and consumer, today's digital and social media - from which consumers shape cultural and political 
narratives via their own user-generated content - have removed those barriers and blurred the line between expert and layperson. Consequently, citizens are ostensibly empowered by a technological revolution comparable to Gutenberg's movable type of five centuries before. However, the extent to which citizens are truly endowed by digital media is subject to debate (Hindman, 2009). In any case, the digital revolution has placed the traditionally defined expert - in political science, medicine, climatology or any other field - under direct challenge: the unqualified pundit can now engage social media and disseminate opinions disguised as facts. Given individuals' ability to build online communities among equally ill-informed users, and to do so via a powerful hand-held device without ever leaving home, it appears that social media has indeed produced the quintessential 'armchair expert', where anyone from esteemed scholar to partisan activist to polemical 'keyboard warrior' can enter the public sphere and assume the expert's mantle (Brotherton, French and Pickering 2013; Habermas, 1992; Strom 2019).

As we begin the third decade of the twenty-first century, I argue that we must define the political commentator more broadly, as a figure who, by virtue of academic qualification, partisan experience or other authoritative position - but not an amateur polemicist - is sought by the news media for regular comment on political developments. That commentator will engage with print, online and broadcast media, and fulfil their role in one or more of four ways: by offering journalists background detail; by providing direct quotes; by supplying opinion articles to print and online media; and by appearing on - or even hosting - radio and television current affairs programs. Importantly, for the purposes of this article, I distinguish the term 'political commentator' from the broader 'public intellectual' label. While they share common ground, not all political commentators boast intellectualism or even academic qualifications, and not all public intellectuals comment on politics in the news media.

Despite the power of the political commentator, however defined, to frame political news between and during election campaigns - and, therefore, to influence electors' voting choices - it is surprising that scholarly assessment of the role is relatively scant in the social science literature. I therefore argue for the importance of political actors, journalists and voters fully understanding the role of the political commentator, especially during periods of electoral volatility, rapid technological innovation and, of course, at a time when citizens - increasingly mistrustful of established political institutions - are drawn to less-reputable media and the populist politics they cultivate. This article addresses this lack of scholarly reflection.

\section{Context}

As a Queensland-based political commentator of more than 20 years' experience, I begin with anecdotal evidence of how the role of the academic political commentator in Australia is not only misunderstood but often received with hostility. This is undoubtedly rooted in Australians' increasing mistrust of Australian political institutions and elites - what Crosby (2017) labels the 'trust deficit' - that saw just 59 per cent of Australian voters in 2019 express satisfaction with their democratic system, the lowest level since Australia's 1975 constitutional crisis (Cameron and McAllister, 2019: 15). Concomitantly, 75 per cent of Australians 
- the highest level on record - now agree that politicians 'look after themselves', while just 25 per cent - the lowest level on record - agree that 'people in government can be trusted' (Cameron and McAllister, 2019: 15). A 2019 Ipsos poll found similarly high levels of suspicion of Australia's mainstream news media, with 38 per cent refusing to trust television and radio, and 41 per cent mistrustful of newspapers and magazines (Ipsos, 2019). However, not all evidence gives cause for pessimism: the 2019 Edelman survey found that trust among Australia's 'informed public' had risen four points to 59 per cent over the previous year, and risen by seven points to 46 per cent among the 'mass population' over the same period (Edelman, 2019).

Even so, wide and potentially growing scepticism - too often born out of an antiexpert bias (Nichols, 2017) and on occasion conspiracy memes (Goertzel, 2010: 493-4) - sees around 3 per cent of Australian parents refuse to vaccinate their children (Leask, Danchin and Berry, 2017). Similarly, 12 per cent of Australian voters deny anthropogenic climate change despite the broad scientific consensus (Kilvert, 2019). Perhaps most sobering is the You.Gov survey that found just 84 per cent of all Americans - and just 66 per cent of those aged between 18 and 24 - are convinced the earth is round (Nace, 2018).

The corollary is that news consumers, already suspicious of political and intellectual 'elites', are becoming increasingly cynical about the academic commentator whom they deem to be 'out of touch', irrelevant or simply corrupted by an allegedly left-leaning higher education system (Hartle, 2017). The roots of such attitudes are undoubtedly found in Giddens' description of the public intellectual's work as one inherently 'characterised by a certain exclusivity of audience' (Giddens, in Dallyn, Marinetto and Cederström 2015: 1036). The following examples of online readers' comments, taken from a single newspaper column written by this author (Williams, 2017b) satirising the political fortunes of Pauline Hanson's One Nation party, offer typical qualitative evidence:

What a load of rubbish; Williams is a political scientist! What on earth does that mean? Seems like he spends his day in a lab and that vapour from some toxic mix has escaped and affected his brain ... Another Leftist exaggeration! How about telling some real facts! ... The lefty's [sic] are packing bricks in their Reggie's ... 'all Left leaning media tarts and academia [should be] forcibly removed from Queensland ... The good doctor seems to have trouble convincing the electors, going by these electors on this blog. I'd like to see him go out in the labour force like the majority of working people and see how he likes this socialist lefty government who caters to public servants and union men only ... I can't decide if you lack intellect to understand this our [sic] are just so arrogant and removed from everyday reality that you truly don't understand ... Stay at Uni Paul, you won't have to do any real work and can carry on living your fantasy life.

\section{Research questions, hypotheses and method}

This article poses three research questions: What functions do political commentators perform in an anti-elitist age of civic mistrust? What types of commentators exist to fulfil these roles? And how have innovations in media and communications technology shaped these types? 
I answer these questions with five arguments: first, political commentators today perform one or more of three key functions ('public educator', 'value educator' and 'polemicist'); second, social media's disruption of mainstream journalism and traditional patterns of news consumption has broadened and flattened the definition of political commentator; third, such disruptions have been deleterious to journalism and democracy; fourth, we can today identify seven discrete types of commentator in Australia; and fifth, in response to a new postmodern political environment, the academic political commentator must range far beyond the traditional 'descriptive' function - describing how affairs currently are - and move to a 'normative' function in which commentators assert how public affairs should be. These, then, are the two broad functions required of political commentary in Australia today, with the three broad roles and seven specific types of political commentator explored in detail below.

This article employs a blend of methodologies. In assuming a phenomenological approach derived from the author's personal experience (Dukes, 1984), it also employs a hermeneutic method of interpretation of data derived from that experience (Laverty, 2003). These largely interpretative approaches - steered by an understanding that social science research is necessarily different from the hard sciences - are balanced by a scientific social anthropology method of 'pattern matching and categorization' (Larson and Monarchi 2004: 350). Indeed, categorisation lies at the heart of this research, in which the author has 'observed [and] segment[ed] the observed phenomena into units [according to] the characteristics or internal properties of [these] categories' (Chenail, 2012: 2; Stokoe, 2012). The strength of the categorisation method is self-evident: 'Human beings are believed to be especially good at pattern matching and categorization - indeed ... categorization is basic to all human intellectual activities' (Larson and Monarchi, 2004: 350). Yet the limitations of these methods must also be noted, including that 'the reasoning behind human categorizations is often unclear' and that 'the human ability to categorize and recognize patterns breaks down as data sets grow in size' (2004: 350). Moreover, as Dukes (1984: 197) argues, phenomenological approaches can lead to 'fuzzy thinking'. Collier, LaPorte and Seawright (2012: 218-19) acknowledge this problem, and the difficulty in accurately measuring and locating 'departure' points for each category - a shortcoming inevitably leading to a degree of researcher subjectivity.

\section{The commentator's evolution from descriptive to normative analysis}

Critically, the evolution of the modern commentator's role is consistent with the oftcited definition of political culture established by esteemed political scientist Colin A. Hughes (1973: 133):

[Political culture is] that part of culture which relates to the operation of a political system; it is the set of beliefs held by members of that culture about the way in which the political system and its actors behave, and the way in which they should behave, and is therefore both descriptive and normative.

In short, this article argues that the role of the modern political commentator is to raise 'guardrails' around political and media narratives to remind voters what is, 
and what is not, acceptable political behaviour in any robust democracy. For example, in the case of cabinet appointing a partisan loyalist to a senior position within a statutory authority - without public advertisement or the interviewing of candidates assessed against objective criteria - the political commentator will describe the background of the appointee and their appointment process in descriptive terms, then ideally establish in normative terms the impropriety of such an appointment by outlining the historical conventions of public sector accountability, and by explaining how cronyism is anathema to evidence-based policymaking and a merit-based public service. As above, normative analysis inherently involves a degree of subjective - and often culturally specific - evaluation as to what is, and what is not, acceptable behaviour. The potential danger among political commentators of even the highest academic standing is, therefore, a desire to 'police' the public narrative.

Notwithstanding this, there are at least four reasons why the modern political commentator must add a normative function to their descriptive role. The first is the paucity of comprehensive civics education in Australian school curricula (Williams, 2018), and the subsequent 'sense of crisis in young peoples' political knowledge' that ensues (Peterson and Bentley, 2017: 44). The triennial Australian Election Study has regularly found, for example, that a majority of adult Australians fail to correctly answer a number of standard questions regarding the basic operations of the Australian political system. ${ }^{1}$ In short:

How can we expect young people to engage with the community, to value the vote, to distinguish between quality journalism and online ramblings when we don't even teach such basics as the separation of powers in the history of democracy? (Williams, 2019)

A second reason is found in the changing nature of news production, dissemination and consumption, explored below, where resource-poor newsrooms - challenged by declining print sales, online subscriptions, broadcast ratings and advertising revenue - are compromised in their ability to conduct long-term investigative journalism and, faced with commercial pressures, instead meet short-term consumer demand for superficially sensationalist and conflict-driven content too often buttressed by public relations 'spin' (Lamble, 2013: 57-61). The result has been a 'flattening out' and 'dumbing down' of political news that limits voters' access to the policy information required for informed vote choices.

Third, the emergence of online 'fake news', 'gaslighting' and other deliberate misinformation, outlined below, has created a 'hothouse' for conspiracy theories that require qualified commentators to separate fact from fiction (Davis and Ernst, 2019). Satisfyingly, the internet has seen something of a reversal of the 'fake news' phenomenon since the 2016 US presidential election campaign, which saw one in four social media news stories deemed 'fake' (Bovet and Makse, 2019: 1). In a bid to eliminate explicitly false statements, Twitter in 2019 announced a ban on all political advertising, while Facebook - while refusing a similar moratorium launched a 'fact-checking programme' immediately after the 2016 election that appears to have reduced the 'fake news' flow (Lee, 2019). Moreover, according to the 2019 Australian Digital News Report, more Australians are fact-checking news, with 62 per cent of Australian consumers 'concerned about what is real or fake on the internet'. The report also found that 36 per cent of consumers 'have checked 
several different sources to check the accuracy of a story', with 26 per cent now using 'more reliable sources of news' (Fisher et al., 2019a).

Last, and related to the above, commentators must include normative analysis, given the increasing propensity of voters - too often encouraged by social media memes sourced from partisan stakeholders and other unqualified users - to ignore empirically supported evidence (for example, that migration creates jobs for local workers) and rely instead on feelings or suspicions (that immigrants steal local workers' jobs) (Hoon and McLaren, 2015). Given, as former United Kingdom Prime Minister Theresa May acknowledged, that voters are increasingly polarised in their world views, and that erroneous assumptions are increasingly difficult to counter (Woodcock, 2019), it is critical for the modern commentator not just to describe the functions of such political institutions as cabinet, parliament, the Constitution, the separation of powers and the rule of law, but also to assert the democratic value of these institutions so that consumers might continue to enjoy their democratic freedoms.

\section{Literature review}

The work of the political commentator has received a degree of scholarly attention internationally. In the United States, for example, the esteemed media theorist and newspaper columnist Walter Lippmann $(1920,1922,1925)$ reflected on the role in his work on journalism, democracy and public opinion. Subsequent scholars have drawn heavily upon Lippmann; they include Nimmo and Newsome (1997), who compiled a sourcebook of America's most significant twentieth-century commentators and the historical circumstances in which they worked. Bro (2012) also applied Lippmann to his own exploration of the 'division between neutrality and partiality' and the anatomisation of Lippman's commentary into 'first, second, third and fourth order issues'. While such analyses generally conclude the self-evidential power of the political commentator to shape public opinion, Brewer and Sigelman (2002: 32), by contrast, argue that commentators, while offering colour to 'the game of politics', fall short of challenging 'the dominant emphasis of media campaign coverage'.

Scholarly reflection is also found in the European literature. Lacqueur (1998), for example, explored the commentary offered by German-American journalist and philosopher Hannah Arendt, while May (2010) argued that British philosopher John Ruskin, a respected nineteenth-century social commentator, also shaped contemporary debates on political economy. Meanwhile, Godden (2013: 55) argued that economists, as 'public intellectuals' in Britain's economically challenged 1920s and 1930s, moved far beyond their brief of 'commenting on policy decisions' to one where they attempted to 'influence public sentiment'. In a modern context, Denisova (2017: 40) found that political commentators in authoritarian postcommunist Russia allowed 'micro-bloggers' to engage in parody as a 'protective shield' against retribution for critical comment.

Scholarly reflection on the role of the political commentator is comparatively scant in Australia. Significant attempts to explore this area nonetheless include Gardiner's (1988) study of sixteenth-century English writer George Cavendish, and Rundle's (2007) assessment of 'power intellectuals' during John Howard's conservative prime ministership (1996-2007). Coper (2014) also added to our 
understanding when he synopsised the life of constitutional and electoral commentator Geoffrey Sawer, with the conclusion that Sawer regarded his work in constitutional law 'a little less like a technical lawyer and a little more from the perspective of the total operation of the governmental system' (2014: 402). However, it was veteran Queensland political commentator Paul Reynolds who offered perhaps the most profound reflection in the Australian literature when, exactly 30 years ago, he published a seminal article, 'On being a political commentator', that quartered the academic commentator's role.

Reynolds' first function is that of 'significant other': the commentator is not usually employed by a media organisation, but remains 'at large', most often in the employ of a university. As such, commentators over time can become 'opinion leaders in their field of expertise' (Reynolds 1989: 139).

Reynolds' second element is the commentator's independence:

the political commentator's veracity will only be accepted by the media, and its public, if his or her interpretations are seen to be independent, in the sense of not being tied to a partisan position or representing the opinions of some set of vested interests (1989: 139).

Third, given the news media's 'ceaseless flow of information', the commentator must regularly be accessible to journalists.

Last, and perhaps most critically, Reynolds argues that the academic commentator must be able 'to distil often complex questions for general dissemination'. This occurs on two levels. First, journalists, who are rarely experts in political theory, will often 'frame' - that is, 'select some aspects of a perceived reality and make them more salient' (Entman, 1993: 52) - a news story from the detail the commentator supplies. Importantly, Reynolds (1989: 141-2) argues that the relationship between journalist and commentator is a 'two-way street': commentators will supply historical context and theory, while journalists will relate recent and often covert developments. Second, Reynolds argues that political commentators will adopt something of a 'didactic' role for news consumers. He adds (1989: 142) that voters'

lack of knowledge whets the appetite in many, who simply want to know, for example, how parliament functions, why there is a federal constitution, where the political parties developed from or what purpose the High Court fulfils.

\section{The disruptive effects of digital and social media}

While 30 years might be of little consequence to the stable party politics of Australian democracy, the three decades since Reynolds' analysis are a virtual eon in the evolution of media and communications technology. Australians in 1989 were yet to encounter subscription television, and the World Wide Web, email and digital newspapers would not be used widely for some years. With costly and underpowered computers in 1989 confined to desktop word-processing functions, social media via inexpensive handheld 'tablets' and 'smart' mobile phones were even more distantly inconceivable notions.

Australians in 1989 also consumed news on the momentous events of that year the collapse of the Berlin Wall, the overthrow of Romanian dictator Nicolae Ceaussescu, the pro-democracy rallies in China's Tiananmen Square - from 
hard-copy newspapers and magazines, and from radio and television bulletins. Critically, this was news as we had understood it since the early twentieth century: objectively written and source-balanced stories produced by professionally trained journalists who selected content via scientifically derived 'news values'. By routinely passing stories through a series of news 'gates', journalists would produce only factchecked journalism, where polarised quotes were reconciled by the political commentator's objective analysis. Moreover, stories were written in 'inverted pyramid' form to answer the 'who, what, when, where, why and how' of the day's events (Lamble, 2013: 53-5), with opinion pieces in newspapers and magazines, and commentaries on current affairs programs, clearly separated from news content. In short, consumers then were in no doubt as to where reporting ended and opinion began.

The late 1980s was also a time of largely homogenous patterns of news consumption. Most families listened to the same radio news bulletin and read the same hard-copy newspaper over breakfast, and viewed the same evening 'event' television news bulletins - chosen from just a handful of networks - at the same moment as the rest of Australia (Bainbridge, 2015a: 145, 152). But this homogeneity had largely been disrupted by the second decade of the twenty-first century as Australia reached an internet penetration of almost 90 per cent (Fisher, 2019), and especially as Australians increasingly turned to online news sources, including those from less reputable websites and social media 'feeds'. The 2019 Australian Digital News Report, for example, found that 43 per cent of Australians relied upon online sources as their 'main' source of news, with 18 per cent employing social media 'feeds' as their main news source (Fisher et al., 2019b: 13). Online and social media news consumption levels among younger Australians are higher still. Indeed, given the numerous studies of how new media technologies can shape electors' voting choices - with a disproportionate number of young voters endorsing minor or micro parties to potentially disrupt established party systems - the role of digital technology has long been accepted as integral to social, cultural and political analysis (Gibson and McAllister, 2011; Ward, 2008; Williams, 2006).

Additional contexts offer cause for concern: just 9 per cent of Australians are prepared to pay for 'quality' online news, with 44 per cent believing news is 'too negative'. Indeed, 62 per cent of Australians now 'avoid' the news, a rise of five points since 2017. Australians are also the 'lightest' news consumers among the 38 nations surveyed, with 48 per cent consuming news 'once a day or less', significantly higher than the global mean of 34 per cent (Fisher et al., 2019b: 13). This dramatic shift in news consumption presents obvious democratic deficits. The first is that consumers' shift to 'free' online news - from an established news site without a 'paywall' or from a social media news 'feed' - has seen a steady decline in the consumption of traditional news sources. The year 2019, for example, saw a 1.3 per cent fall in Australian newspaper readership (print and online) over the previous 12 months (Roy Morgan, 2019) while in 2017, just 50 per cent of American adults turned to traditional television news as their 'regular' news source, down from 57 per cent in 2016 (Matsa, 2018). These declines in turn saw advertisers flee traditional media for significantly cheaper online options. The loss of employment, vehicle and real estate advertising - once the staple of print newspaper revenue - has been particularly damaging to newspapers' financial viability, with News Corp's The Australian losing 6 per cent in revenue in 2018 alone (Butler, 2019). 
Problematically, this loss of steady revenue has forced the shedding of journalists' jobs - around 3,000 in the decade to 2018 (Zion et al., 2018) - as print and broadcast newsrooms rationalise their place in an already fiercely competitive market.

The subsequently leaner newsrooms have produced two regrettable effects. The first is the increasing inability of news companies to dedicate staff to long-form investigative journalism that might require months of deep research to uncover, for example, government or corporate corruption. Second, the World Wide Web has merely multiplied the number of news 'holes' that journalists are required to fill on an hourly basis. To fill these 'holes', time-poor journalists, especially in regional and rural Australia, too often succumb to public relations: studies reveal between 30 and 80 per cent of all news content is 'sourced from, or significantly influenced by, public relations practitioners' (Lamble, 2013: 59). Given that public relations officers in Australia today outnumber journalists by a factor of four to one (Donovan, 2012), the description of Australia as a 'PR state' (Ward, 2003) appears accurate.

This phenomenon has in turn produced a 'shallowing out' of news coverage, where deep analysis of political ideas and party policy is increasingly supplanted by superficial impressions of leaders' qualities, including dress, voice and personal appeal (Liu, 2019: 14-15). ${ }^{2}$ Given the commercial pressure to attend to consumer tastes, journalists are also steered towards sensationalist frames - corruption, sex, violence - underpinned by the news values of conflict, novelty and celebrity (Bainbridge, 2015b: 237-55; Gillman, 2015: 281-6; Lamble, 2013: 45-52). Another effect of this phenomenon is the 'horse-race' coverage of election campaigns that sees policy analysis increasingly supplanted by ubiquitous public opinion polls, which frame stories around 'who's winning' and 'who's losing' while simultaneously disproportionately highlighting campaign 'gaffes' (Goot, 2013).

A second democratic deficit is found in social media's application of selective algorithms that, in recommending news articles, blogs and videos to users based on previous consumption patterns, creates for consumers a 'filter bubble' or 'echo chamber' in which ideological biases and cultural prejudices are reinforced rather than challenged (Zimmer et al., 2019). This also predisposes electorates to a political discourse fought with subjective rhetoric and not objective facts. The power and reach of amateur online polemics masquerading as commentary is equally worrying, given that political blogs in the United States are 'the most widely read form of US political commentary' (Hindman, 2009: 133).

Third, and as outlined above, the dissemination of 'fake news' - ranging from the merely subjectively framed news article to the entirely falsified story - rests at the core of postmodern politics; in describing all truth as relative, this gives rise to a post-fact milieu (McIntyre, 2018: 1-11). The reverse is also true: real news, objectively written by professional journalists reporting independently verified facts, is too often dismissed by political extremists as 'fake' when its content proves embarrassing. This phenomenon was no better illustrated than in January 2017 when, just days after newly elected US President Donald Trump swore an oath of office, political commentator and Trump apologist Kellyanne Conway repeated Trump media adviser Sean Spicer's claim that public attendance at Trump's inauguration ceremony was the highest on record. Interviewers challenged Spicer and Conway's claim and produced photographic evidence clearly indicating 
significantly larger crowds at Barack Obama's inauguration. Conway rebutted this assertion of fact and labelled her demonstrably false counter-claims 'alternative facts' (Sinderbrand, 2017; Williams, 2017a). The conclusion is clear: in postmodern political discourse, facts are sublimated by opinions and feelings in a bid to win rhetorical arguments (McIntyre, 2018: 11).

\section{Three roles of the political commentator}

The broadening of the political and media landscapes described above necessitates a comparable broadening in our understanding of the roles commentators perform today. The first role is that of 'public educator'. Here, the political commentator objectively informs journalists and news consumers as to the significance of the day's events - for example, the calling of a 'snap' election or the delivery of a surplus budget - while very often drawing upon historical precedent for meaningful context. Importantly, this information is most usually delivered without opinion or other value judgement.

A second, and more recent, role is that of the 'value educator'. Here, the political commentator frames the impact of the day's events - for example, a premier's refusal to dismiss a cabinet minister who had lost the confidence of the House - in both descriptive and normative terms, anatomising not only what has occurred in terms of significance but, more critically, outlining how that event is, or is not, consistent with the tenets and conventions of Westminster democracy. This role inherently brings with it a degree of subjectivity, but one unrelated to parochial partisanship.

Third, and most recently, a small and growing group of political commentators emerging most usually from outside academia - has adopted the role of 'polemicist'. That role, most often practised without scholarship, is designed to champion partisan positions to 'win' rhetorical debates. Notable examples include the campaign to discredit anthropogenic climate change and the framing of minority rights as undesirable 'political correctness'. It is intuitive that as social media accounts grow in number, so too do the number of polemicists. Where, for example, there were just 30 million Twitter accounts in 2010, that number had grown elevenfold by 2019 to 330 million (Statista, 2019). Moreover, according to the Pew Center, Twitter use among those commenting on politics was distributed unevenly, with just 10 per cent of users in 2019 generating 97 per cent of all political tweets (Baca, 2019). This appears to confirm, as Hindman (2009) has argued, the 'myth' that digital media have enhanced democratic participation and empowerment.

It is critical to note that academic political commentators can, and do, practise the first and second roles - but rarely the third - while professional polemicists rarely demonstrate the first two roles. The article now explores the seven types of political commentator performing these roles while engaging with traditional and digital media today.

\section{Seven types of political commentator}

The first type is the traditional 'academic commentator' who, with postgraduate qualifications in political science and a wealth of research experience and acquired empirical evidence, objectively fulfils the first and second roles when engaging with 
the news media. This commentator rarely boasts journalism qualifications or experience and, while perhaps commissioned as a regular or irregular newspaper columnist, will almost never host their own broadcast program despite appearing as a regular guest on some.

The second type is the 'senior journalist' who, given their status as senior writer or broadcaster, will enjoy the opportunity to add to their hard news reporting any number of 'break out' newspaper columns of analysis, or serve as a regular 'insider' guest on radio and television current affairs programs. This commentator also fulfils the first and second roles with substantial objectivity.

A third, and increasingly common, type is the 'group commentator' who, as a senior representative of a think-tank or pressure group, will arrive at their role with a vested interest. Importantly, this commentator - for example, a business group leader or trade union president - will likely find themselves commenting on a variety of issues during election campaigns.

Fourth, and closely related to the above, is the 'retired politician' who, in regularly critiquing the day's events, will draw comparisons to their own time in government. As above, this type's inherently partisan background prevents genuine objectivity, although retirement often affords the luxury of criticising members of one's own party, if only along factional lines.

The 'professional polemicist' - based on the long-established 'shock jock' radio presenter and now more recently found among antagonistic newspaper columnists comprises a fifth type that dwells most commonly on the ideologically hard right. This type is paid - and encouraged via newspaper subscriptions, online 'clicks' and broadcast ratings - to cultivate outrage over such issues as immigration, refugees, climate change, transgender rights and the modern education system. Consequently, this type eschews objectivity.

A sixth and more recently emerged type is the 'lived experience' commentator. As a person directly affected by a social or cultural phenomenon - sexual assault or domestic violence, for example - this commentator will be regularly sought by the news media for insight into a specific social ill, and rarely sought to comment on issues beyond their own lived experience.

The seventh type is the 'celebrity' commentator who, by virtue of a preestablished media profile - excellence in sport or the performing arts, for example - offers a range of opinions on topics far beyond their expertise. Fundamentalist Christian sportsmen and women condemning same-sex relationships, and breakfast television hosts calling for a ban on Muslim immigration, are two recent examples.

Two additional categories sitting outside any meaningful definition of 'political commentator' must also be considered, if only to concede their ability to shape public narratives. The first is the unpaid 'amateur polemicist' who, often described as a 'troll' (Binns, 2012), will use blogs and other social media to disseminate conspiracy theories, normalise extremist political views and generally cultivate friction via offensive posts. A second outlying type is the 'incidental poster' who publishes comments - occasionally or regularly and often with vitriol - on online news sites to question the accuracy of an article, the appropriateness of a journalist's frame or even the credibility of a neutral commentator (Williams, 2015). Few would define either types as a 'political commentator'. 


\section{Conclusion}

Despite the power that political commentators potentially wield in the shaping of media narratives - and to shape electors' vote choices between and during election campaigns - the political commentator's role in any liberal democracy has largely been ignored in the social science literature. This article seeks to partially fill this gap by arguing such analysis is critical given current levels of public mistrust of political institutions and expertise, and especially so as technological innovations rapidly disrupt traditional patterns of news media production, dissemination and consumption. A mixed methodological approach has been adopted to argue that political commentators today perform one or more of three functions ('public educator', 'value educator' and 'polemicist'), and that social media's disruption of mainstream journalism has necessarily broadened and flattened the definition of political commentator, with deleterious effects on journalism and democracy the result. The article subsequently identifies seven discrete types of commentator in contemporary Australia while arguing that, in a postmodern media environment, the academic political commentator must not only continue to engage in a 'descriptive' role but also offer 'normative' analysis of current events. Given the political commentator's rapidly transforming place in the public sphere, this article ultimately concludes that further analysis is required to alert commentators, political actors, journalists and voters to the need to erect 'guardrails' to postmodern democratic discourse where expertise is so often disparaged.

\section{Acknowledgement}

The author thanks the anonymous referees for their helpful comments on an earlier draft of this article.

\section{Notes}

1 In 2010, just 45 per cent of Australians surveyed by the Australian Election Study responded correctly to the statement 'The Senate election is based on proportional representation' (true). The results in 2001 and 2007 were 41 and 47 per cent respectively. In answer to 'The Constitution can only be changed by the High Court' (false), just 36, 37 and 33 per cent answered correctly in 2001, 2007 and 2010. In answer to 'No one may stand for Federal Parliament unless they pay a deposit' (true), correct answers were recorded among just 30, 28 and 21 per cent. In answer to 'The longest time allowed between federal elections for the House of Representatives is four years' (false), just 25, 28 and 30 per cent answered correctly. In answer to 'There are 75 members of the House of Representatives' (false), just 25, 33 and 42 per cent answered correctly. See Gibson and McAlister (2014).

2 Queensland Liberal-National Party leader Deb Frecklington attracted significant opprobrium in late 2019 for criticising the clothing choices of Labor leader Annastacia Palaszczuk whom, Frecklington argued, had become a 'Princess Premier' (see Lang, 2019: 10; McKay, 2019: 6).

\section{References}

Baca, Marie 2019. 'Most of the political tweets you see are from a minority of users, a Pew study says', Washington Post, 25 October, https:/www.washingtonpost.com/ technology/2019/10/24/most-political-tweets-you-see-are-small-minority-users. 
Bainbridge, Jason 2015a. 'Television: The zoo', in Jason Bainbridge, Nicola Goc and Liz Tynan (eds), Media and journalism: New approaches to theory and practice (3rd ed.). Melbourne: Oxford University Press.

— 2015b. 'Celebrity'. in Jason Bainbridge, Nicola Goc and Liz Tynan (eds), Media and journalism: New approaches to theory and practice (3rd ed.). Melbourne: Oxford University Press.

Binns, Amy 2012. 'Don't feed the trolls! Managing troublemakers in magazines' online communities', Journalism Practice 6(4): 547-62.

Bovet, Alexandre and Makse, Hernán A. 2019. 'Influence of fake news in Twitter during the 2016 US presidential election', Nature Communication 10 (7): 1-14.

Brewer, Paul and Sigelman, Lee 2002. 'Political scientists as color commentators: Framing and expert commentary in media campaign coverage', Politics/Press 7(1): 23-35.

Bro, Peter 2012. 'License to comment', Journalism Studies, 13(3): 433-46.

Brotherton, Robert, French, Christopher and Pickering, Alan 2013. 'Measuring belief in conspiracy theories: The generic conspiracist beliefs scale', Frontiers in Psychology 14: $1-15$.

Butler, Ben 2019. 'News Corp Australia revenues fall as advertising drops and subscriptions stay flat', The Guardian, 9 August, https:/www.theguardian.com/ australia-news/2019/aug/09/news-corp-australia-revenues-fall-as-advertising-dropsand-subscriptions-stay-flat.

Cameron, Sarah and McAllister, Ian 2019. The 2019 Australian federal election: Results from the Australian Election Study. Canberra: Australian National University, https://australianelectionstudy.org/wp-content/uploads/The-2019-Australian-FederalElection-Results-from-the-Australian-Election-Study.pdf.

Chenail, Ron 2012. 'Categorization', in The Sage Encyclopedia of Qualitative Research Methods. Thousand Oaks, CA: Sage, https://methods.sagepub.com/base/download/ ReferenceEntry/sage-encyc-qualitative-research-methods/n41.xml.

Collier, David, Laporte, Jody and Seawright, Jason 2012. 'Putting Typologies to Work: Concept Formation, Measurement, and Analytic Rigor', Political Research Quarterly. 65(1): 217-32.

Coper, Michael 2014. 'Geoffrey Sawer and the art of the academic commentator: A preliminary sketch biographical sketch', Federal Law Review 42(2): 241-51.

Crosby, Sam 2017. The Trust Deficit, Melbourne: Melbourne University Publishing.

Dallyn, Sam, Marinetto, Mike and Cederström, Carl 2015. 'The academic as public intellectual: Examining public engagement in the professionalised academy', Sociology 49(6): 1031-46.

Davis, Angelique and Ernst, Rose 2019. 'Racial gaslighting', Politics, Groups, and Identities 7(4): 761-74.

Denisova, Anastasia 2017. 'Parody micro-bloggers as chroniclers and commentators on Russian political reality', Demokratizatsiya 25(1): 23-42.

Donovan, David 2012. 'The death of journalism and the victory of PR', Independent Australia, 22 February, https://independentaustralia.net/politics/politics-display/thedeath-of-journalism-and-the-victory-of-pr,3971.

Dukes, Sheree 1984. 'Phenomenological methodology in the human sciences', Journal of Religion and Health, 23(3): 197-203. 
Edelman 2019. The 2019 Edelman Trust Barometer, https:/www.edelman.com.au/ research/trust-barometer-2019.

Entman, Robert 1993. 'Framing: Toward clarification of a fractured paradigm', Journal of Communication, 43(4): 51-8.

Fisher, Caroline. 2019. 'Australia', Digital News Report, http://www.digitalnews report.org/survey/2019/australia-2019.

Fisher, Caroline, Park, Sora, Lee, Jee, Fuller, Glen and Sang Yoonmo 2019a. 'Australians are fact-checking to combat fake news', Canberra Times, 13 June, https://www.canberratimes.com.au/story/6213952/australians-are-fact-checking-tocombat-fake-news.

— 2019b. Digital News Report: Australia 2019. Canberra: University of Canberra, https://apo.org.au/sites/default/files/resource-files/2019/06/apo-nid240786-1366986.pdf.

Gardiner, L. R. 1988. 'George Cavendish: An early Tudor political commentator?' Australian and New Zealand Association of Medieval and Early Modern Studies, 6: 77-87.

Gibson, Rachel and McAllister, Ian 2011. 'Do online election campaigns win votes? The 2007 Australian "YouTube” election', Political Communication 28(2): 227-44.

-2014. 'New media, elections and the political knowledge gap in Australia', Journal of Sociology 51(2): 337-53.

Gillman, Sarah 2015. 'News values and news culture in a changing world', in Jason Bainbridge, Nicola Goc and Liz Tynan (eds), Media and journalism: New approaches to theory and practice (3rd ed.). Melbourne: Oxford University Press.

Godden, Chris 2013. 'Observers, commentators, and persuaders: British interwar economists as public intellectuals', History of Political Economy 45 (Supp. 1): $38-67$.

Goertzel, Ted 2010. 'Conspiracy theories in science', Outlook: European Molecular Biology Organization 11(7): 493-9.

Goot, Murray 2013. 'How the pollsters called the horse race: Changing polling technologies, cost pressures, and the concentration on the two-party-preferred', in Carol Johnson and John Wanna (eds), Abbott's gambit: The 2013 Australian federal election. Canberra: ANU Press.

Habermas, Jürgen 1992 [1962]. The structural transformation of the public sphere: An inquiry into a category of bourgeois society, trans. Thomas Burger and Frederick Lawrence. Cambridge: Polity Press.

Hartle, Terry 2017. 'Why most Republicans don't like higher education', The Chronicle of Higher Education, 19 July, https://www.chronicle.com/article/Why-MostRepublicans-Don- $\mathrm{t} / 240691$.

Hindman, Matthew 2009. The myth of digital democracy, Princeton, NJ: Princeton University Press.

Hoon, Gihoon and McLaren, John 2015. Are immigrants a shot in the arm for the local economy? Working Paper 21123, National Bureau of Economic Research, https:// www.nber.org/papers/w21123.pdf.

Hughes, Colin A. 1973. 'Political culture', in H. Mayer and H. Nelson (eds), Australian Politics: A Third Reader. Melbourne: Cheshire.

Ipsos 2019. 'Australians trust the media less', Trust the Media Study, 25 June, https:// www.ipsos.com/en-au/australians-trust-media-less-ipsos-trust-media-study. 
Kilvert, Nick 2019. 'Climate change survey shows Australians want action on emissions, but are divided on nuclear', $A B C$ News, 10 September, https://www.abc.net.au/news/ science/2019-09-10/climate-of-nation-australia-attitudes/11484690.

Lacquer, Walter. 1998. 'The Arendt cult: Hannah Arendt as political commentator', Journal of Contemporary History 33(4): 483-96.

Lamble, Stephen, 2013. News as it happens: An introduction to journalism (2nd ed.). Melbourne: Oxford University Press.

Lang, Kylie 2019. 'Grounded Deb’s her own woman', Sunday Mail, 29 December, p. 10.

Larson, Kai and David Monarchi 2004. 'A mathematical approach to categorization and labeling of qualitative data: The latent categorization method', Sociological Methodology 34(1): 349-92.

Laverty, Susann M. 2003. 'Hermeneutic phenomenology and phenomenology: A comparison of historical and methodological considerations', International Journal of Qualitative Methods 2(3): 21-35.

Leask, Julie, Danchin, Margie and Berry, Nina 2017. 'Australians' attitudes to vaccination are more complex than a simple "pro" or "anti" label'. The Conversation, 9 March, http://theconversation.com/australians-attitudes-to-vaccination-are-morecomplex-than-a-simple-pro-or-anti-label-74245.

Lee, David 2019. 'Matter of fact-checkers: Is Facebook winning the fake news war?' BBC News, 2 April, https://www.bbc.com/news/technology-47779782.

Lippman, Walter 1920. Liberty and the news. New York: Harcourt, Brace and Howe.

- 1922. Public opinion. New York: Harcourt, Brace and Howe.

— 1925. The phantom public. Piscataway, NJ: Transaction.

Liu, Sarah 2019. 'Cracking gender stereotypes? Challenges women political leaders face', Political Insight, March: 12-15.

Matsa, Katherine 2018. 'Fewer Americans rely on TV news; what type they watch varies by who they are', Pew Research Center, 5 January, https://www.pewresearch.org/ fact-tank/2018/01/05/fewer-americans-rely-on-tv-news-what-type-they-watch-variesby-who-they-are.

May, Christopher 2010. 'John Ruskin's political economy: 'There is no wealth but life', The British Journal of Politics and International Relations 12(1): 189-204.

McIntyre, Lee 2018. Post-truth. Cambridge, MA: MIT Press.

McKay, Jack 2019. 'Critics hot back at Mean Girl Deb', Courier Mail, 30 December, p. 6.

Nace, Trevor 2018. 'Only two-thirds of American Millennials believe the Earth is round', Forbes Magazine, 4 April, https://www.forbes.com/sites/trevornace/2018/04/04/onlytwo-thirds-of-american-millennials-believe-the-earth-is-round/\#453d969c7ec6.

Nichols, Tom 2017. The death of expertise: The campaign against established knowledge and why it matters. New York: Oxford University Press.

Nimmo, Dan and Newsome, Chevelle 1997. Political commentators in the United States in the 20th century: A bio-critical sourcebook. Westport, CT: Greenwood Press.

Petersen, Andrew and Bentley, Brendan 2017. 'A case for cautious optimism? Active citizenship and the Australian civics and citizenship curriculum', Asia Pacific Journal of Education 37(1): 42-54.

Reynolds, Paul 1989, 'On being a political commentator', Australian Journalism Review 11: 139-42. 
Roy Morgan 2019. 'Over 15.7 million Australians read newspapers in print or online', 7 February, http://www.roymorgan.com/findings/7878-australian-newspaper-printreadership-and-cross-platform-audiences-december-2018-201902070454.

Rundle, Guy 2007. 'Power intellectuals in the Howard era', Arena Magazine 91: 25-31.

Shuman, Daniel and Greenberg, Stuart 2003. 'The expert witness, the adversary system, and the voice of reason: Reconciling impartiality and advocacy', Professional Psychology: Research and Practice 34(3): 219-24.

Sinderbrand, Rebecca 2017. 'How Kellyanne Conway ushered in the era of "alternative facts"', Washington Post, 23 January, https://www.washingtonpost.com/news/thefix/wp/2017/01/22/how-kellyanne-conway-ushered-in-the-era-of-alternative-facts.

Statista 2019. 'Number of monthly active Twitter users worldwide from 1st quarter 2010 to 1 st quarter 2019', https://www.statista.com/statistics/282087/number-ofmonthly-active-twitter-users.

Stokoe, Elizabeth 2012. 'Moving forward with membership categorization analysis: Methods for systematic analysis', Discourse Studies, 14(3): 277-303.

Strom, Timothy 2019. 'Marketing Fascism', Arena 159: 7-8.

Ward, Ian 2003. 'An Australian PR state?', Australian Journal of Communication 30(1): 25-42.

2008. 'Kevin07. Labor's pitch to Generation YouTube', Social Alternatives 27(2): $11-15$.

Williams, Paul D. 2006. 'The greening of the Queensland electorate?', Australian Journal of Political Science, 41(3): 325-37.

— 2015. 'Trolls need to be unmasked', Courier Mail, 2 January, p. 26.

-2017a. 'In a post-truth existence, the alternatives to facts are grim', Courier Mail, 26 January, p. 50.

2017b. 'Step through the looking glass for a state run by One Nation', Courier Mail, 16 February, p. 20.

— 2018. 'Politics, media and the teaching of civics and citizenship in an age of institutional mistrust', The Social Educator 36(1): 39-51.

— 2019. 'Parents' vital role in saving school system', Courier Mail, 11 December, p. 26.

Woodcock, Andrew 2019. 'Theresa May takes swipe at "polarised politics” which brought her down in final speech', The Independent, 17 July, https:/www.independent.co.uk/ news/uk/politics/theresa-may-speech-brexit-boris-johnson-prime-minister-jeremyhunt-a9009616.html.

Zimmer, Franziska, Scheibe, Katrin, Stock, Mechtild and Stock, Wolfgang 2019. 'Fake news in social media: Bad algorithms or biased users?' Journal of Information Science Theory and Practice 7(2): 40-53.

Zion, Lawrie, Dodd, Andrew, Ricketson, Matthew, Sherwood, Merryn, Winarnita, Monika, O’Donnell, Penny and Majoribanks, Timothy 2018. 'New research reveals how Australian journalists are faring four years after redundancy', The Conversation, 5 December, https://theconversation.com/new-research-reveals-how-australianjournalists-are-faring-four-years-after-redundancy-107520. 